\title{
Wireless Power Theft Monitoring And Controlling Unit for Substation
}

\author{
Saritha I G ${ }^{1}$, Sowmyashree $\mathrm{M} \mathrm{S}^{2}$, Thejaswini $\mathrm{S}^{3}$, Surekha R Gondkar ${ }^{4}$ \\ Department of Telecommunication Engineering, BMSIT $T^{1,2,3,4}$ \\ Assistant prof ${ }^{1,2,3}$, Associate prof ${ }^{4}$.
}

\begin{abstract}
Power theft problem now days causes huge loss to electricity board, it is necessary to prevent so that a lot of power can be saved. This paper determines the greatest opportunity for energy savings by continuously monitoring and controlling power theft from the electric meter by taking readings from it . The normal practice for power theft is to short the input and output terminals or to place magnet on the wheel in case of old meters. By wireless power theft monitoring it is possible to sense the current flow through the line \& energy feedback using a circuit breaker. This system prevents the illegal usage of electricity, which can be solved automatically without any human control.The implementation of this system will save large amount of electricity.
\end{abstract}

Index Terms: Microcontroller, Zigbee, keiluvision, Power meter.

\section{INTRODUCTION}

An electric meter is a device used for measuring the amount of electrical energy supplied to a commercial or residential building. Due to the increasing cost of electricity, security and tampering in electric meters has become a major concern for government agencies over the globe. Moreover in populous countries like China and India, tampering in electric meter and energy theft have become common. Electric meters can be manipulated, thus causing them to stop,even bypassing the meter. Consumers those who are tamper with electric meter, effectively and efficiently use power without paying for it. This theft or fraud can be dishonest as well as dangerous .Electric meter security is made as major issue in many countries today.

Wireless Power Theft Monitoring Unit use remote monitoring method to prevent power theft. It is necessary to present this method to electricity department. This Unit also use Radio technology to monitor wireless meter reading. If there will be difference in wireless reading and installed meter reading, then it is easy to detect theif.

\section{Working}

In this unit, a micro controller is interfaced with an energy metering circuit, current sensing circuit, Zigbee communication link, and contactor to make or break power line.

At the sub-station a PC is connected with a Zigbee link to communicate with all energy meters and a buzzer.

In normal condition, micro controller reads energy pulses and current signals. If current is drawing and energy pulses are normal, then no power theft is being done and the output is connected. If current is drawing and energy pulses are not flowing, then it indicates that power theft. So microcontroller trips the output using relay unit .This information is sent to substation using wireless communication. In the substation, it receives the information in the form of digital codes and on decoding it, we can know at which place power theft occurred.

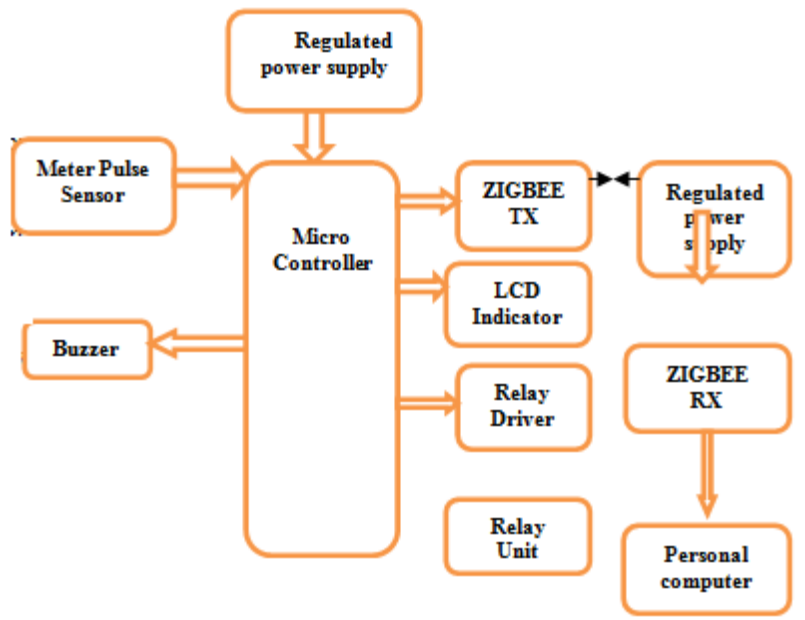




\section{Microcontroller P89V51RD2}

\section{Components Used}

Microcontroller is a computer on a single chip (IC), designed with all the in built facilities, both software and hardware, to control and monitor any device, process, equipment, machine [1][2].In general electronics, electrical, electro mechanical systems applicable to variety of industries. With such a huge applications for Microcontrollers the market of them is vast. And thus many versions of micro controllers from the different manufacturers are Intel, Zilog, Toshiba, Sharp, Motorola, Microchip, Atmel and Philips. This basic architecture consists of the following features:

- An eight bit ALU

- 32 discrete I/O pins (4 groups of 8) which can be individually accessed

- Two 16 bit timer/counters

- Full duplex UART

- 6 interrupts with 2 priority levels

- 128 bytes of on board RAM

- Separate 64Kbyte address spaces for DATA and CODE memory

- $5 \mathrm{~V}$ Operating voltage from 0 to $40 \mathrm{MHz}$

- 64KB of on-chip flash memory(program) with ISP (In-System Programming) and IAP (In-Application Programming)

- Low EMI mode (ALE inhibit)

- TTL- and CMOS-compatible logic levels

\section{ZIGBEE}

ZigBee is one of the global standards of wireless communication protocol designed to use low power digital radio signals for personal area networks and formulated by the relevant task force under the IEEE 802.15 working group environment. The WPAN Low Rate ZigBee is the newest and it provides specifications for devices that have low data rates and consume very low power and are thus characterized by long battery life. Other standards like IrDA and Bluetooth address high data rate applications such as video, voice and LAN communications.

\section{Relay unit}

Relays use an electromagnetic coil to move the poles of a switch when it is powered on. There are three pairs of connections known as common, normally open and normally closed. The centre terminal block is the common (CO) connection and is connected to either the upper or lower terminal block depending on the state of the relay. When not switched, the centre terminal block is connected to the normally closed (NC) lower terminal block. When switched on the centre terminal block is connected to the normally open (NO) upper terminal block.

\section{LCD display}

A LCD (Liquid crystal display) is a display device which is very thin and flat made up of any number of color or monochrome pixels arrayed in front of a light source. Each pixel consists of a column of liquid crystal molecules suspended between two transparent electrodes and two polarizing filters, the axes of polarity of it are perpendicular to each other. Without liquid crystals between them, light passing through one filter would be blocked by the other. The liquid crystal twists polarization light entering one filter to allow it to pass through the other.

\section{Relay driver}

To make a relay operate, we have to pass a suitable 'pull-in' and 'holding' current (DC) through its energized coil. And generally relay coils are designed to operate from a particular supply voltage, usually $5 \mathrm{~V}$ or $12 \mathrm{~V}$, in the case of many of the small relays used for electronics circuit design. In each case the coil has a resistance which will draw the right pull-in and holding currents when it is connected to supply voltage. So the basic idea is to select a relay with a coil designed to operate from the supply voltage you're using for your control circuit and then provide a suitable 'relay driver' circuit so that our low-power circuitry can control the current through the relay's coil. Typically it will be between $25 \mathrm{~mA}$ and $70 \mathrm{~mA}$.

\section{Buzzer}

The word "buzzer" comes from the increasing noise that it made when they were electromechanical devices operated from stepped-down AC line voltage at 50 to 60 cycles. Ring or a beep sounds are commonly used to indicate that a buttons been pressed. 


\section{Regulated power supply}

A regulated power supply essentially consists of a voltage regulating device and an ordinary power supply. The output from an ordinary power supply is fed to the voltage regulating device that provides the final output. Irrespective of variations in the ac input voltage or variations in output current the output voltage remains constant.

\section{System Design}

Operational frame work of this paper can be divided into two major Condition which is shown below

\section{To detect overload:-}

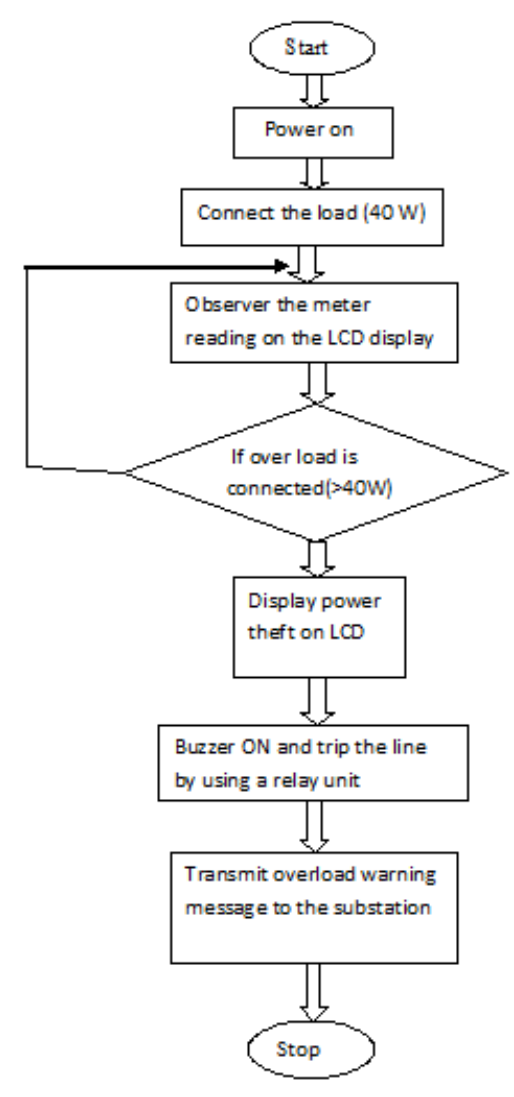

To detect power theft:-

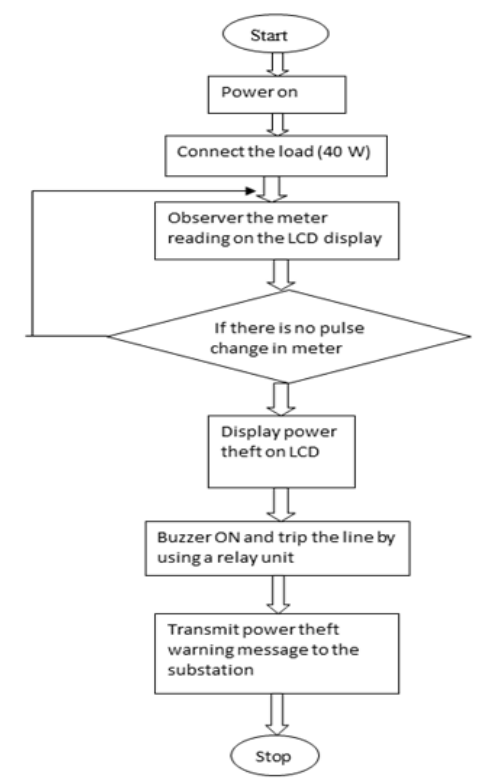




\section{Results}

The practical result obtained was same as the expected result. An embedded system to detect Power theft has been designed can able to perform the following operations successfully.

\section{Stage1:-}

once the primary tests are achieved the power supply is given to the load and the bulb glows as shown in figure below

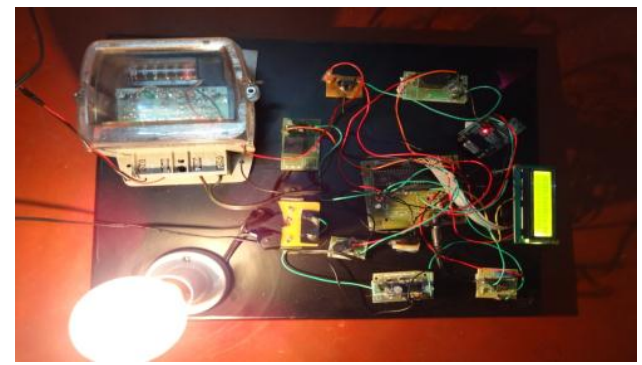

Stage 2: The meter detects the number of pulse consumed by the load and display on the LCD.

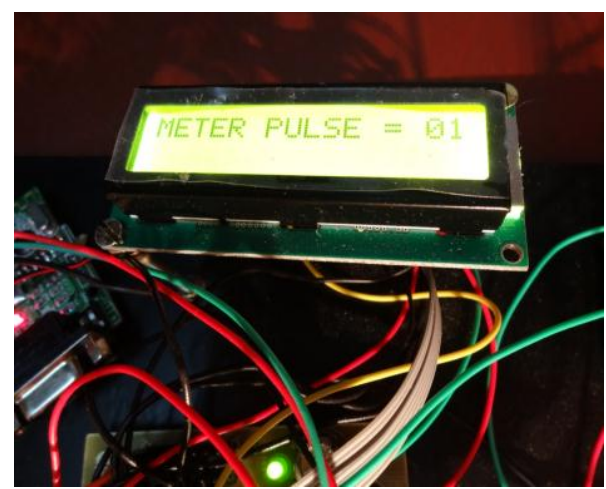

Stage 3: The circuit will send the information about the activities going on at the meter board to the substation receiver.

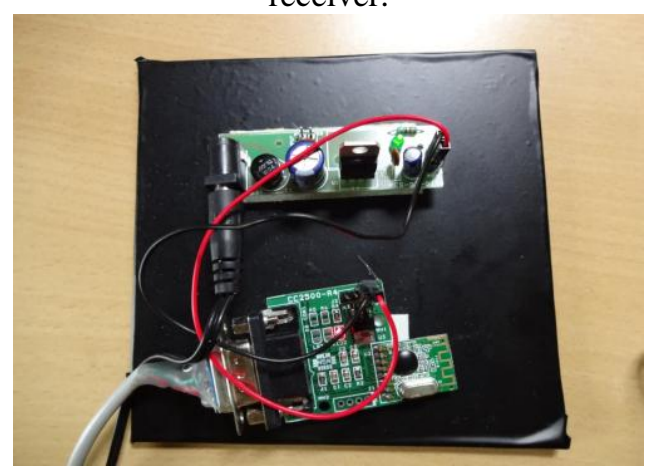

Stage 4: When power theft or over load is detected the warning message is displayed on LCD and the sub-

When over load is detected: station PC.

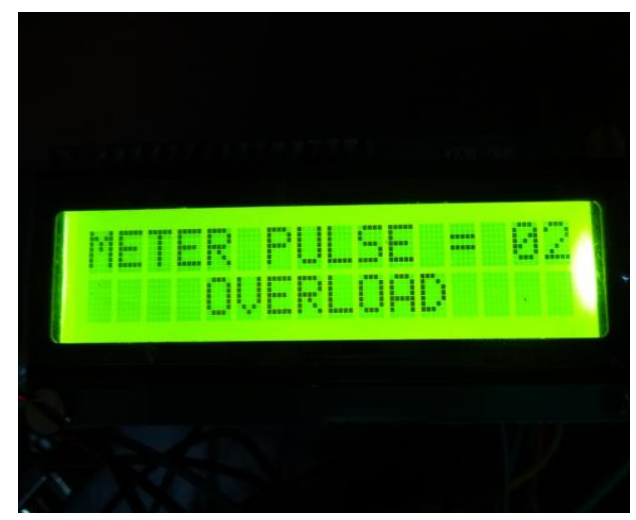


When power theft detected:

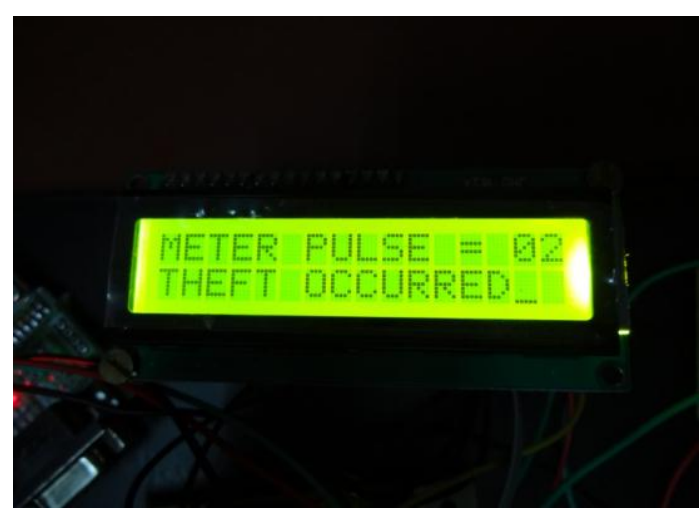

Message displayed in substation PC:

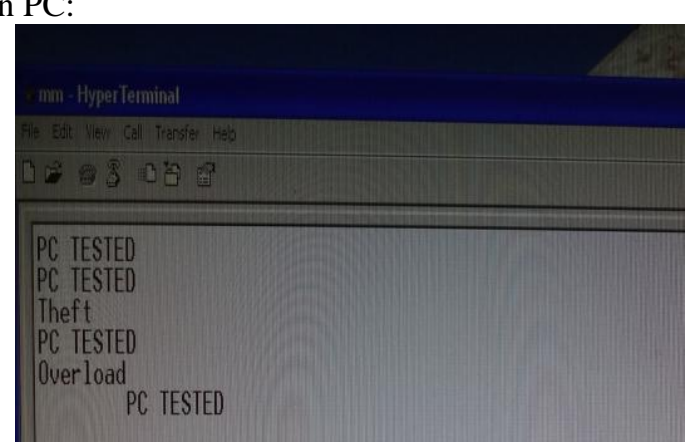

Final view

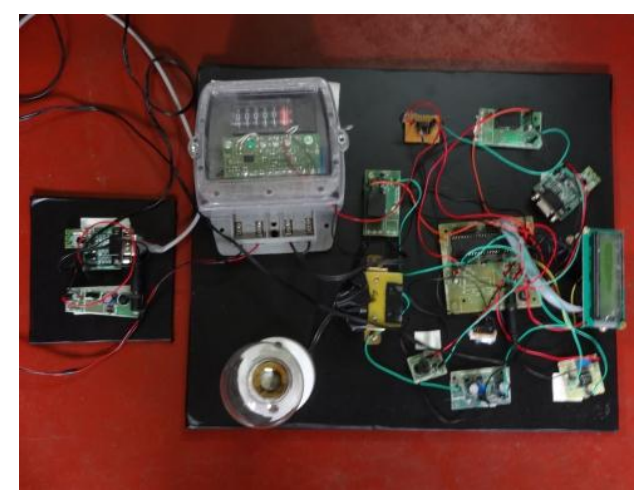

\section{Conclusion}

The Power theft is an economic crime that adversely affects all utility customers. Utilities estimate that 0.5 to 1.0 percent of all customers steal from them and that their annual losses exceed $\$ 1.7$ billion in power and $\$ 1.3$ billion in natural gas[8]. Power Theft is a non ignorable crime that is highly prevented. Thus an attempt is made in this paper to detect power theft and controlling it. In future the proposed model can be improved by adopting modern meters, tamper proof seals and tamper resistance locks to discover tampering and to secure electric meter against it with more accurate results.

\section{References}

[1] Milan Verle- "Architecture \& programming of 8051 ".

[2] Mazidi, Mazidi, McKinlay- "The 8051 microcontroller and Embedded Systems".

[3] M.A. Oliveira and C.C. Barioni, "Technical loss calculation bydistribution system segment with corrections from measurements,"Proc.20th international Conference and Exhibition on Electricity Distribution, Prague, Czech Republic, June 2009, pp. $1-4$.

[4] T. B. Smith, "Electricity theft- comparative analysis," Energy Policy,vol. 32, pp. 2067-2076, Aug. 2003.

[5] "Overview of power distribution," Ministry of Power, Govt. of India,[Online]. Available: http://www.powermin.nic.in

[6] A. Pyasi and V. Verma, "Improvement in electricity distribution efficiency to mitigate pollution IEEE ISEE," Proc. IEEE International Symposium on Electronics and the Environment, San Francisco, California, May 2008, pp. 1-1.

[7] Brown, David S. \& Ahmed Mushfiq Mobarak. 2009. "The Transforming Power of Democracy:Regime Type and the Distribution of Electricity.” American Political Science Review 103(2):193-213.

[8] 10 Supra note 1. 11 Supra note 9. 12J. J. Gray. ed., "Theft of Utility Services;' Criminal and Civil Investigation Handbook (New York: McGraw Hill Book Company, 1981), p. 7- 126.8. 